\title{
Moving Load Spectrum for Analyzing the Extreme Response of Bridge Free Vibration
}

\author{
Jinhua Li $(\mathbb{D}$ and Huantao Zhang \\ Department of Civil Engineering, East China Jiaotong University, No. 808 Shuanggang St., Nanchang 330013, China \\ Correspondence should be addressed to Jinhua Li; jinhua.lee@foxmail.com
}

Received 27 October 2019; Accepted 3 January 2020; Published 22 January 2020

Academic Editor: Pedro Galvín

Copyright (C) 2020 Jinhua Li and Huantao Zhang. This is an open access article distributed under the Creative Commons Attribution License, which permits unrestricted use, distribution, and reproduction in any medium, provided the original work is properly cited.

In order to more effectively establish the relationship between moving load speed and the extreme response of bridge free vibration, a novel analysis method is presented based on the moving load spectrum, which is deduced from Fourier transform in this paper. By analyzing the moving load spectrum in detail, the moving load velocities which lead to the extreme responses of bridge free vibration under single moving constant force or harmonic force are obtained, and the corresponding formula for calculating the moving load velocity which leads to the maximum response of bridge free vibration is put forward. Finally, the moving load spectrum for analyzing the extreme response of bridge free vibration is validated by a large number of calculations in the time domain in this paper. The results show that the moving velocities corresponding to the extreme points in the moving load spectrum are consistent with the velocities corresponding to the extreme points of the bridge vibration response obtained in the time domain, and the forced and free vibration displacement responses of bridge are not the largest when the single moving constant force or harmonic force passes through the bridge at the resonant velocity compared to other speeds.

\section{Introduction}

High-speed railway bridge, which plays a significant role in the rapid development of the high-speed railway [1-3], not only ensures the smoothness of railway lines but also prevents too much settlement. Due to the simple architecture and convenient construction, the simply supported beam has become the preferred structure for the construction of high-speed railway bridge. However, as the train speed increases continuously, the problems arising from the vibration response of the bridge are more apparent. Therefore, the dynamic analysis of bridges under high-speed train loads has drawn the attention of many researchers from different countries. A series of theoretical studies on the vibration response and control of the simply supported bridge in the high-speed railway has been carried out in the last few decades [4-6]. However, due to modern transportation becoming much heavier and faster, this research area remains an exciting and challenging one.
The study of the vibration response of the train passing through bridges can trace back to the 18th century. Willis [7] obtained an analytical solution to the vibration response of the bridge by simplifying the train and bridge model when considering the cause of the collapse of the Chester bridge. After the 1960s, with the development of computers, a series of studies on the solution of the bridge dynamic response have been made by Maunder [8], Weaver et al. [9], Gbadeyan and Oni [10], Frýba [11], Michaltsos [12], and Savin [13], and these studies provide the theoretical basis for future research studies. With the rapid development of Chinese railway, especially high-speed railway, the quantities of research studies aiming at railway bridges have also increased ( $\mathrm{Li}$ and Su [14], Li and Qiang [15], Zhang et al. [16], Xia et al. [17], Li et al. [18]). The research range extends from vertical vibration of bridges to other vibration responses such as lateral vibration and torsion of bridge. However, the bridge resonance problem is noted in the study of the bridge vibration response. If the railway bridge is subjected to resonance all year round, 
it will lead to rail damage, ballast instability, concrete cracking, and so on. Therefore, the problem of resonance caused by moving loads acting on railway bridges has been a hot topic (Ju and Lin [19], Yang et al. [20], Yau and Yang [21], Mao and Lu [22], Luu et al. [23], Lu et al. [24], Yang and Yau [25]).

For the vibration response of a bridge under the action of the actual train, the coupling effect of the train bridge should be considered (Wang et al. [26], He [27]), but the bridge resonance under the train-bridge coupling cannot be solved analytically. Therefore, for the study of bridge resonance under train-bridge coupling, the influence of bridge span, vertical and lateral stiffness, train formation, and vehicle wheelbase parameters can only be judged by numerical analysis. However, to simplify the study of the bridge resonance under trainload, it is usual to simplify the trainload into the form of moving constant force. Xia et al. [28, 29] firstly studied several different forms of resonance that may occur when a train passes a bridge at a certain speed and then analyzed the vibration of simply supported beams under moving loads such as single moving force, equally spaced moving load columns, and nonequidistant moving loads.

It is known that a moving load travels through a bridge; the vibration response can be divided into two stages, such as the forced vibration period and the free vibration period. Due to the increase of the train speed, the time that the train acts on the bridge is shorter and shorter and the time of the bridge free vibration is much longer than that of the forced vibration. Moreover, the amplitude of the bridge free vibration response decreases slowly due to the small damping. Apparently, the free vibration is more harmful to the bridge than the forced vibration. Therefore, most scholars have begun to pay attention to the bridge free vibration response caused by the moving loads (Xia et al. [29], Pesterev et al. [30], Museros et al. [31], Kumar et al. [32]). Pesterev et al. [30] found that after a single moving load passes through a simply supported bridge at different speeds, the free vibration response of the bridge has a series of extreme points, but the corresponding velocities of these extreme points are not resonant velocities. Moreover, Xia et al. [29] mentioned in his book that the maximum of the free vibration displacement response of a simply supported beam under a single moving load does not increase monotonously with the increase of the load speed and some peaks appear at certain speeds. Museros et al. [31] studied the free vibration response of simply supported beams under moving loads and found that there are a series of extreme points in the bridge vibration response where the maximum and minimum values appear alternately; however, the corresponding velocities of these extreme points are also not resonant velocities. Thus, it should be noted that the moving load possessing the resonant velocity does not mean that the bridge will show resonance response. In fact, when the moving constant load passes through the simply supported beam at the resonant speed, the bridge free vibration response does not reach the maximum response.

In the abovementioned literature, these research studies on the bridge vibration response under moving loads are from the perspective of time domain, while few documents involve frequency-domain analysis. Relative to the time domain, the frequency-domain analysis has many advantages, such as intuitive and no need to solve differential equations. Therefore, in this paper, in order to more effectively establish the relationship between the moving load speed and the extreme response of bridge free vibration, a convenient and effective frequency-domain analysis method is presented based on the moving load spectrum, which is deduced from Fourier transform. In this paper, firstly for the moving loads such as a moving constant force and harmonic force, the moving load spectrums are deduced in the frequency domain by Fourier transform considering the modes of bridge. Then, by analyzing the extreme values of the amplitude spectrum of the moving load, the maximum free vibration response of bridge under all possible velocities of the traveling load is studied. Furthermore, the effective formulas are presented to conveniently determine the velocities of the moving load corresponding to the maximum amplitude of the bridge free vibration response without intensive computations. Finally, the moving load spectrum for analyzing extreme response of bridge free vibration is validated by a large number of calculations in the time domain in this paper.

\section{Moving Load Spectrum in Frequency Domain}

2.1. A Single Moving Constant Force Acting on the Simply Supported Bridge. Although the moving load is a relatively simple model of vehicle, it can be very useful to engineers and researchers when examining more realistic models of moving vehicles, providing reasonable approximations of the desired results and helping to devise a plan of attack on the problem. For a simply supported bridge with a span of $L$ under the action of a single constant force $p_{0}$ with the constant velocity $v$ as shown in Figure 1, the motion equation can be expressed as follows:

$$
\begin{gathered}
m_{\mathrm{b}} \frac{\partial^{2} y_{\mathrm{b}}(x, t)}{\partial t^{2}}+c_{\mathrm{b}} \frac{\partial y_{\mathrm{b}}(x, t)}{\partial t}+\mathrm{EI} \frac{\partial^{4} y_{\mathrm{b}}(x, t)}{\partial x^{4}}=f_{\mathrm{b}}(x, t) \\
f_{b}(x, t)=\delta(x-v t) \cdot p_{0} \cdot\left[U(t)-U\left(t-\frac{L}{v}\right)\right]
\end{gathered}
$$

where $y_{\mathrm{b}}(x, t)$ is the vertical displacement of the bridge at $t$ time and $x$ position and $f_{\mathrm{b}}(x, t)$ is the moving constant force, which can be regarded as a pulse load since the action time of the moving constant force is limited. Assuming that the bridge is the Euler-Bernoulli beam, the properties of the bridge remain unchanged along the span direction; that is, both the unit length stiffness EI and the unit length mass $m_{\mathrm{b}}$ of the bridge are constant. Also, assuming that the damping of the bridge is viscous Rayleigh damp, the damping coefficient $c_{\mathrm{b}}$ has the orthogonality of mode shape. $\delta$ is the Dirac function, and $U$ is the Heaviside function.

The vertical displacement of the bridge $y_{\mathrm{b}}(x, t)$ at the $x$ position and $t$ time can be expressed as a linear combination of the bridge vibration modes:

$$
y_{\mathrm{b}}(x, t)=\sum_{j=1}^{\infty} q_{\mathrm{b} j}(t) \phi_{j}(x),
$$




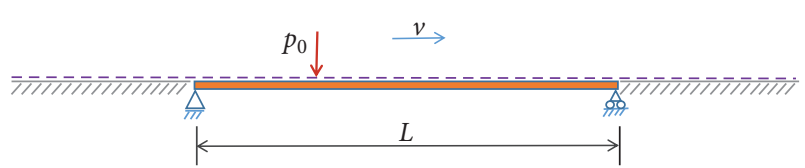

Figure 1: Bridge under a moving constant force.

where $q_{\mathrm{b} j}(t)$ is the generalized coordinates and $\phi_{j}(x)$ is the $j$ th mode of the bridge. For the simply supported beam with the equal section, $\phi_{j}(x)=\sin (j \pi x / L)$. Substituting equation (3) into equation (1), multiplying $\phi_{m}(x)$ on both sides of the equation, and integrating along with the bridge span from zero to $L$, then

$$
\begin{aligned}
& \sum_{j=1}^{\infty} \int_{0}^{L} \phi_{m}(x) \cdot m_{\mathrm{b}} \cdot \phi_{j}(x) \ddot{q}_{\mathrm{b} j}(t) \mathrm{d} x \\
& \quad+\sum_{j=1}^{\infty} \int_{0}^{L} \phi_{m}(x) \cdot c_{\mathrm{b}} \cdot \phi_{j}(x) \dot{q}_{\mathrm{b} j}(x) \mathrm{d} x \\
& \quad+\sum_{j=1}^{\infty} \int_{0}^{L} \phi_{m}(x) \cdot \mathrm{EI} \frac{d^{4} \phi_{j}(x)}{\mathrm{d} x^{4}} q_{\mathrm{b} j}(t) \mathrm{d} x \\
& \quad=\int_{0}^{L} \phi_{m}(x) f_{b j}(x, t) \mathrm{d} x .
\end{aligned}
$$

Considering the orthogonality of modes, the equation of motion can be decoupled as follows:

$$
\ddot{q}_{\mathrm{b} j}(t)+2 \xi_{\mathrm{b} j} \omega_{\mathrm{b} j} \dot{q}_{\mathrm{b} j}(t)+\omega_{\mathrm{b} j}^{2} q_{\mathrm{b} j}(t)=\frac{2}{m_{\mathrm{b}} L} f_{\mathrm{b} j}(t),
$$

where $\omega_{\mathrm{b} j}$ and $\xi_{\mathrm{b} j}$ are the $j$ th circular frequency and modal damping ratio of the beam, respectively, and $f_{\mathrm{b} j}(t)$ is the $j$ th mode moving load:

$$
f_{\mathrm{b} j}(t)=p_{0} \cdot \sin \frac{j \pi v t}{L} \cdot\left[U(t)-U\left(t-\frac{L}{v}\right)\right] .
$$

Then, by the Fourier transform for two sides of equation (5), the spectrum of the $j$ th mode displacement response can be expressed as follows:

$$
Q_{\mathrm{b} j}(\omega)=H_{j}(\omega) F_{\mathrm{b} j}(\omega) .
$$

Accordingly, in the frequency domain, the spectrum of the bridge displacement response at the $x$ position caused by the moving constant force can be represented in the series form as follows:

$$
Y_{\mathrm{b}}(x, \omega)=\sum_{j=1}^{\infty} Q_{\mathrm{b} j}(\omega) \cdot \phi_{j}(x)=\sum_{j=1}^{\infty} H_{j}(\omega) F_{\mathrm{b} j}(\omega) \cdot \phi_{j}(x),
$$

where $H_{j}(\omega)$ is the transfer function:

$$
H_{j}(\omega)=\frac{2}{m_{\mathrm{b}} L}\left(-\omega^{2}+2 i \omega \xi_{\mathrm{b} j} \omega_{\mathrm{b} j}+\omega_{\mathrm{b} j}^{2}\right)^{-1}
$$

Also, $F_{\mathrm{b} j}(\omega)$ is the moving load spectrum of the $j$ th mode moving constant force, that is, the Fourier transform of $f_{\mathrm{b} j}$ $(t)$ :

$$
\begin{aligned}
F_{\mathrm{b} j}(\omega) & =\int_{-\infty}^{+\infty} f_{\mathrm{b} j}(t) \cdot e^{-i \omega t} \mathrm{~d} t \\
& =\int_{-\infty}^{+\infty} p_{0} \cdot \sin \frac{j \pi v t}{L} \cdot\left[U(t)-U\left(t-\frac{L}{v}\right)\right] \cdot e^{-i \omega t} \mathrm{~d} t \\
& =p_{0} \cdot \frac{j \pi v / L}{\omega^{2}-(j \pi v / L)^{2}}\left[(-1)^{j} \cdot e^{-i \omega(L / v)}-1\right] .
\end{aligned}
$$

Furthermore, the moving load spectrum considering odd modes, $j=1,3,5, \ldots$, can be rewritten as

$$
\begin{array}{r}
F_{\mathrm{bj}}(\omega)=p_{0} \cdot \frac{-2(j \pi L / v) \cdot \cos (\omega L / 2 v)}{(\omega L / v)^{2}-(j \pi)^{2}} \\
\cdot e^{-i(\omega L / 2 v),} \\
j=1,3,5, \ldots .
\end{array}
$$

And for the even modes, $j=2,4,6, \ldots$, the moving load spectrum is expressed as

$$
\begin{array}{r}
F_{\mathrm{b} j}(\omega)=p_{0} \cdot \frac{-2(j \pi L / v) \cdot \sin (\omega L / 2 v)}{(\omega L / v)^{2}-(j \pi)^{2}} \cdot e^{-i(\pi v-\omega L / 2 v),} \\
j=2,4,6, \ldots .
\end{array}
$$

2.2. A Single Moving Harmonic Force Acting on the Simply Supported Bridge. Sometimes, in order to consider the effect of the track irregularity and train frequencies, the moving force model of train load is also regarded as the moving harmonic force $P_{0} e^{i \omega} 0^{t}$ with the constant frequency $\omega_{0}$ and the amplitude $P_{0}$ as shown in Figure 2. Then, the moving harmonic load with speed $v$ acting on a simply supported bridge with the span $L$ can be shown as

$$
f_{\mathrm{h}}(x, t)=\delta(x-v t) \cdot P_{0} e^{i \omega_{0} t} \cdot\left[U(t)-U\left(t-\frac{L}{v}\right)\right] .
$$

And the $j$ th mode moving harmonic force $f_{\mathrm{h} j}(t)$ is

$$
f_{\mathrm{h} j}(t)=P_{0} e^{i \omega_{0} t} \cdot \sin \frac{j \pi v t}{L} \cdot\left[U(t)-U\left(t-\frac{L}{v}\right)\right] .
$$

Accordingly, in like manner, the moving load spectrum of the $j$ th mode moving harmonic force is

$$
\begin{aligned}
F_{\mathrm{h} j}(\omega) & =\int_{-\infty}^{+\infty} f_{\mathrm{h} j}(t) \cdot e^{-i \omega t} \mathrm{~d} t \\
& =\int_{-\infty}^{+\infty} P_{0} e^{i \omega_{0} t} \cdot \sin \frac{j \pi v t}{L} \cdot\left[U(t)-U\left(t-\frac{L}{v}\right)\right] \cdot e^{-i \omega t} \mathrm{~d} t \\
& =P_{0} \cdot \frac{j \pi v / L}{\left(\omega-\omega_{0}\right)^{2}-(j \pi v / L)^{2}}\left[(-1)^{j} \cdot e^{-i\left(\omega-\omega_{0}\right)(L / v)}-1\right] .
\end{aligned}
$$

Similarly, for the $j$ th-mode moving harmonic force, the moving load spectrum with the odd modes can be shown as follows: 


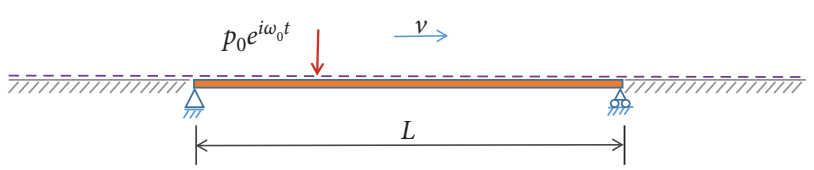

FIgURE 2: Bridge under a moving harmonic load.

$$
\begin{array}{r}
F_{\mathrm{h} j}(\omega)=P_{0} \cdot \frac{-2(j \pi L / v) \cdot \cos \left(\left(\omega-\omega_{0} / 2 v\right) L\right)}{\left(\left(\omega-\omega_{0} / v\right) L\right)^{2}-(j \pi)^{2}} \cdot e^{-i\left(\omega-\omega_{0} / 2 v\right) L,} \\
j=1,3,5, \ldots,
\end{array}
$$

and the moving load spectrum considering the even modes is rewritten as

$$
\begin{aligned}
F_{\mathrm{h} j}(\omega)= & P_{0} \cdot \frac{-2(j \pi L / v) \cdot \sin \left(\left(\omega-\omega_{0} / 2 v\right) L\right)}{\left(\left(\omega-\omega_{0} / v\right) L\right)^{2}-(j \pi)^{2}} \\
& \cdot e^{-i\left(\pi v-\left(\omega-\omega_{0}\right) L / 2 v\right)}, \quad j=2,4,6, \ldots
\end{aligned}
$$

\section{The Moving Load Speeds Corresponding to the Extreme Response of Bridge Free Vibration}

3.1. The Speeds of a Single Moving Constant Force. For the sake of simplification, the effect of bridge damping is neglected, and only the first-order mode of bridge is considered in the following contents. According to equation (8), since considering only the first-order mode of structure, the spectrum of displacement response at the $x$ position of the bridge under a single moving constant force is as follows:

$$
\begin{aligned}
Y_{\mathrm{b}}(x, \omega)= & Q_{\mathrm{b} 1}(\omega) \cdot \phi_{1}(x)=H_{1}(\omega) F_{\mathrm{b} 1}(\omega) \cdot \phi_{1}(x) \\
= & \frac{2}{m_{\mathrm{b}} L} \cdot \frac{1}{-\omega^{2}+\omega_{\mathrm{b} 1}^{2}} \cdot \frac{-p_{0} \cdot(2 \pi L / v) \cdot \cos (\omega L / 2 v)}{(\omega L / v)^{2}-\pi^{2}} \\
& \cdot e^{-i(\omega L / 2 v)} \cdot \sin \left(\frac{\pi x}{L}\right) .
\end{aligned}
$$

Then, the amplitude spectrum of displacement response is the modulus of $Y_{\mathrm{b}}(x, \omega)$, that is, $\left|Y_{\mathrm{b}}(x, \omega)\right|$ :

$$
\begin{aligned}
\left|Y_{\mathrm{b}}(x, \omega)\right|= & \left|H_{1}(\omega)\right| \cdot\left|F_{\mathrm{b} 1}(\omega)\right| \cdot\left|\phi_{1}(x)\right| \\
= & \left|\frac{2}{m_{\mathrm{b}} L} \cdot \frac{1}{-\omega^{2}+\omega_{\mathrm{b} 1}^{2}}\right| \\
& \cdot\left|\frac{p_{0} \cdot(2 \pi L / v) \cdot \cos (\omega L / 2 v)}{(\omega L / v)^{2}-\pi^{2}} \cdot e^{-i(\omega L / 2 v)}\right| \\
& \cdot\left|\sin \left(\frac{\pi x}{L}\right)\right| .
\end{aligned}
$$

For a bridge, the transfer function of vibration response reaches its maximum when the frequency $\omega$ equals the fundamental frequency $\omega_{\mathrm{b} 1}$ of the bridge. Except that, according to equation (17), the magnitude of the displacement amplitude spectrum at the $x$ position of a bridge is only related to the modulus of the moving load spectrum, namely, the amplitude spectrum $\left|F_{\mathrm{b} 1}(\omega)\right|$ of the moving load:

$$
\begin{aligned}
\left|F_{\mathrm{b} 1}(\omega)\right| & =\left|p_{0} \frac{(2 \pi L / v) \cdot \cos (\omega L / 2 v)}{(\omega L / v)^{2}-\pi^{2}} \cdot e^{-i(\omega L / 2 v)}\right| \\
& =\sqrt{2} \cdot p_{0} \frac{(\pi L / v)}{\left|(\omega L / v)^{2}-\pi^{2}\right|} \cdot \sqrt{\left(1+\cos \left(\frac{\omega L}{v}\right)\right)} .
\end{aligned}
$$

It is common knowledge that $\left|Y_{\mathrm{b}}\left(x, \omega_{\mathrm{b} 1}\right)\right|$ is the displacement amplitude of resonance response when the frequency $\omega=\omega_{\mathrm{b} 1}$. Corresponding to $\left|Y_{\mathrm{b}}\left(x, \omega_{\mathrm{b} 1}\right)\right|$, the modulus of the moving load spectrum is $\left|F_{\mathrm{b} 1}\left(\omega_{\mathrm{b} 1}\right)\right|$ :

$$
\left|F_{\mathrm{b} 1}\left(\omega_{\mathrm{b} 1}\right)\right|=\sqrt{2} \cdot p_{0} \frac{(\pi L / v)}{\left|\left(\omega_{\mathrm{b} 1} L / v\right)^{2}-\pi^{2}\right|} \cdot \sqrt{\left(1+\cos \left(\omega_{\mathrm{b} 1} L / v\right)\right)} .
$$

According to equation (17), at any position $x$ of a bridge, the amplitude $\left|Y_{\mathrm{b}}\left(x, \omega_{\mathrm{b} 1}\right)\right|$ increases along with the increase of $\left|F_{\mathrm{b} 1}\left(\omega_{\mathrm{b} 1}\right)\right|$. So, in order to determine the maximum of $\mid Y_{\mathrm{b}}$ $\left(x, \omega_{\mathrm{b} 1}\right) \mid$, it is crucial to analyze the extreme values of $\mid F_{\mathrm{b} 1}$ $\left(\omega_{\mathrm{b} 1}\right) \mid$. According to equation (19), the extreme values are only related to the moving speeds of a constant force $p_{0}$ traveling on a bridge with the natural frequency $\omega_{\mathrm{b} 1}$ and the span $L$. Considering a nondimensional speed $\kappa=\omega_{\mathrm{b} 1} L / v$, then

$$
\left|F_{\mathrm{b} 1}(\kappa)\right|=\frac{\sqrt{2} \pi p_{0}}{\omega_{\mathrm{b} 1}} \cdot \sqrt{\frac{\kappa^{2}}{\left(\kappa^{2}-\pi^{2}\right)^{2}}(1+\cos (\kappa))} .
$$

For the sake of convenience, taking $\sqrt{2}\left(\pi p 0 / \omega_{\mathrm{b} 1}\right)$ as one unit, then the derivative of $\left|F_{\mathrm{b} 1}(\kappa)\right|$ with respect to $\kappa$ can be obtained as follows:

$$
\begin{aligned}
g(\kappa)= & \frac{\mathrm{d}\left|F_{\mathrm{b} 1}(\kappa)\right|}{\mathrm{d} \kappa}=\frac{2\left(\kappa^{2}+\pi^{2}\right)(1+\cos \kappa)+\kappa\left(\kappa^{2}-\pi^{2}\right) \sin \kappa}{2 \sqrt{1+\cos \kappa}\left(\kappa^{2}-\pi^{2}\right)^{2}} \\
& \cdot \frac{\sqrt{(\pi-\kappa)^{2}}}{\pi-\kappa} .
\end{aligned}
$$

The graph of the derivative function $g(\kappa)$ is shown in Figure 3. It is generally known that $\left|F_{\mathrm{b} 1}(\kappa)\right|$ has extreme values when the derivative $g(\kappa)=0$. The first five points corresponding to the derivative $g(\kappa)=0$ can be found in Figure 3, but it is noted that there is a breakpoint in the derivative function $g(\kappa)$ when the nondimensional speed $\kappa=\pi$. Furthermore, according to the changing law of the derivative function curve around five points corresponding to $g(\kappa)=0$, it is acknowledged that the points 1,3 , and 5 correspond to the local maximum points of $\left|F_{\mathrm{b} 1}(\kappa)\right|$ while the points 2 and 4 correspond to the local minimum points, and these local maximum and minimum points appear alternately. For the points $1 \sim 5$, the corresponding $\kappa$ values are listed in Table 1. Substituting the abovementioned extreme points into equation (20) shows that the maximum value of $\mid$ 


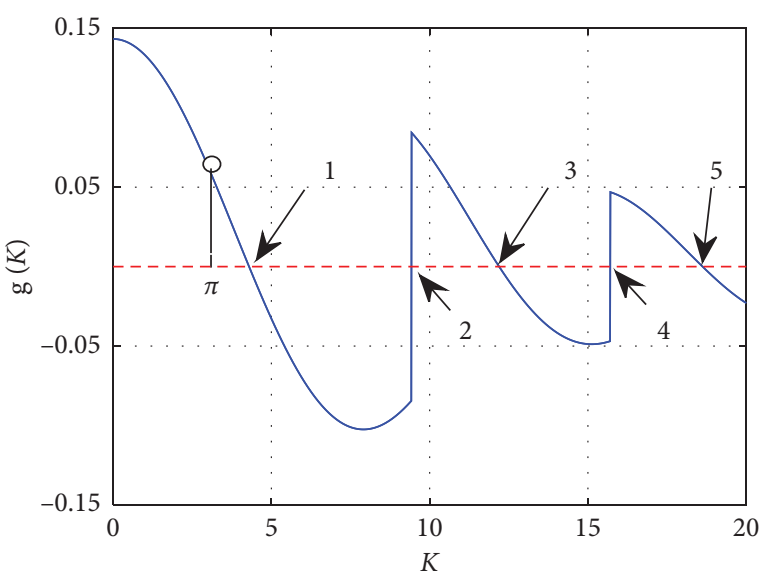

FIgURe 3: Derivative function of $\left|F_{\mathrm{b} 1}(\kappa)\right|$ with respect to $\kappa$.

TABLe 1: Nondimensional speeds corresponding to the extreme points of $\left|F_{\mathrm{b} 1}(\kappa)\right|$.

\begin{tabular}{lc}
\hline Local maximum point & $\kappa$ \\
\hline 1 & 4.34 \\
2 & 9.42 \\
3 & 12.15 \\
4 & 15.70 \\
5 & 18.66 \\
\hline
\end{tabular}

$F_{\mathrm{b} 1}(\kappa) \mid$ is obtained at the extreme point 1 . Moreover, when the frequency $\omega$ is equal to the bridge frequency $\omega_{\mathrm{b} 1}$, the bridge vibration response amplitude spectrum $\left|Y_{\mathrm{b}}\left(x, \omega_{\mathrm{b} 1}\right)\right|$ is the largest, so the corresponding moving load speed according to $\kappa=\omega_{\mathrm{b} 1} L / v$ can be acquired as follows:

$$
V_{|Y| \max }=\frac{\omega_{\mathrm{b} 1} L}{4.34} \text {. }
$$

Note that the speed from equation (22) of a single moving constant load is able to excite the maximum amplitude of the free vibration response of a simply supported bridge.

3.2. Speeds of a Single Moving Harmonic Force. By comparing equations (11a) and (11b) and (15a) and (15b), it can be seen that the difference between the moving load spectrums of two kinds of moving loads (the moving constant force and the moving harmonic force) lies in the harmonic frequency $\omega_{0}$. Therefore, the amplitude spectrum of a single moving harmonic force can be obtained by the same way:

$$
\begin{aligned}
\left|F_{\mathrm{h} 1}(\omega)\right|= & \sqrt{2} \cdot P_{0} \frac{(\pi L / v)}{\left|\left(\left(\omega-\omega_{0} / v\right) L\right)^{2}-\pi^{2}\right|} \\
& \cdot \sqrt{1+\cos \left(\frac{\omega-\omega_{0}}{v} L\right)} .
\end{aligned}
$$

In like manner, the extreme values of $\left|F_{\mathrm{h} 1}(\omega)\right|$ are only related to the moving speeds of a harmonic force $P_{0} e^{i \omega} 0^{t}$ acting on a bridge with the natural frequency $\omega_{\mathrm{b} 1}$ and the span $L$. Let $\kappa=\left|\omega_{\mathrm{b} 1}-\omega_{0}\right| L / v$ be a nondimensional speed, then

$$
\left|F_{\mathrm{h} 1}(\kappa)\right|=\frac{\sqrt{2} \pi P_{0}}{\left|\omega_{\mathrm{b} 1}-\omega_{0}\right|} \cdot \sqrt{\frac{\kappa^{2}}{\left(\kappa^{2}-\pi^{2}\right)^{2}}(1+\cos (\kappa))} .
$$

Taking $\sqrt{2}\left(\pi p_{0} /\left|\omega_{b 1}-\omega 0\right|\right)$ as one unit, the derivative is carried out in the same way and has the same function as equation (21). Therefore, for the extreme points of $\left|F_{\mathrm{h} 1}(\kappa)\right|$, they have the same nondimensional speeds $\kappa$ as listed in Table 1 according to the derivative function $g(\kappa)=0$. In like manner, according to $\kappa=\left|\omega_{\mathrm{b} 1}-\omega_{0}\right| L / v$, the speed of a single moving harmonic force exciting the maximum amplitude of the free vibration response of the bridge can be acquired as

$$
V_{|Y| \max }=\frac{\left|\omega_{\mathrm{b} 1}-\omega_{0}\right| L}{4.34} .
$$

It should be pointed out that the difference between equations (22) and (25) only lies in the frequency $\omega_{0}$ of the moving harmonic force $P_{0} e^{i \omega} 0^{t}$.

\section{Numerical Verification}

In order to verify the effectiveness of the proposed novel method for analyzing maximum free vibration of simply supported bridges based on the moving load spectrum, the results calculated by solving the motion equation of bridge in the time domain as comparison are very important. So, in this paper, three kinds of time-domain methods such as mode decomposition method (MDM), finite element method (FEM), and frequency-domain analysis method (FAM) are programmed by a computer language for calculating the vibration responses of the simply supported bridges under a single moving load with different speeds. MDM and FEM are widely adopted to solve the motion equation while FAM is another method by performing the inverse Fourier transform of $Y_{\mathrm{b}}(x, \omega)$ to obtain the closed solution $y_{\mathrm{b}}(x, t)$.

The bridge and moving load data listed in Table 2 from the literature [33] are utilized as an example; the displacement vibration responses of the bridge under the moving load with a speed of $100 \mathrm{~km} / \mathrm{h}$ are calculated through the above three methods. As shown in Figure 4, it can be seen that the displacements of the bridge midspan solved by the three methods are consistent with the results obtained from the analytical solution (AS) in the literature [33]. Therefore, it is verified that the computer programs of the mentioned three methods are perfectly fine, and the expressions of $Y_{\mathrm{b}}$ $(x, \omega)$ and $F_{\mathrm{b} j}(\omega)$ by the theoretical derivations of the Fourier transform are also utterly correct in this paper.

On the other hand, to illustrate the effect of damping and multimodes of structure, the deformations of the bridge midspan for the undamped and damped cases considering various numbers of vibration modes have been plotted in Figure 5. As can be seen, the effect of damping on the response of the bridge during the action of the moving load is rather small. For this reason, the effect of damping has often been neglected in research concerning the vibration response of bridges. Moreover, the results shown in Figure 5 for the midspan displacement by considering only the first mode are good enough, partly due to the fact that all the antisymmetric modes contribute nothing to the midpoint deflection of the 
TABLe 2: Parameters of a bridge and moving load.

\begin{tabular}{lccccc}
\hline $\mathrm{L}(\mathrm{m})$ & $\mathrm{EI}\left(\mathrm{N} \cdot \mathrm{m}^{2}\right)$ & $\mathrm{m}\left(\mathrm{kg} \cdot \mathrm{m}^{-1}\right)$ & $P_{0}(\mathrm{kN})$ & $\xi$ & $\omega_{\mathrm{b} 1}\left(\mathrm{rad} \cdot \mathrm{s}^{-1}\right)$ \\
\hline 20 & $10^{9}$ & 3000 & 6 & $2.5 \%$ & 14.25 \\
\hline
\end{tabular}

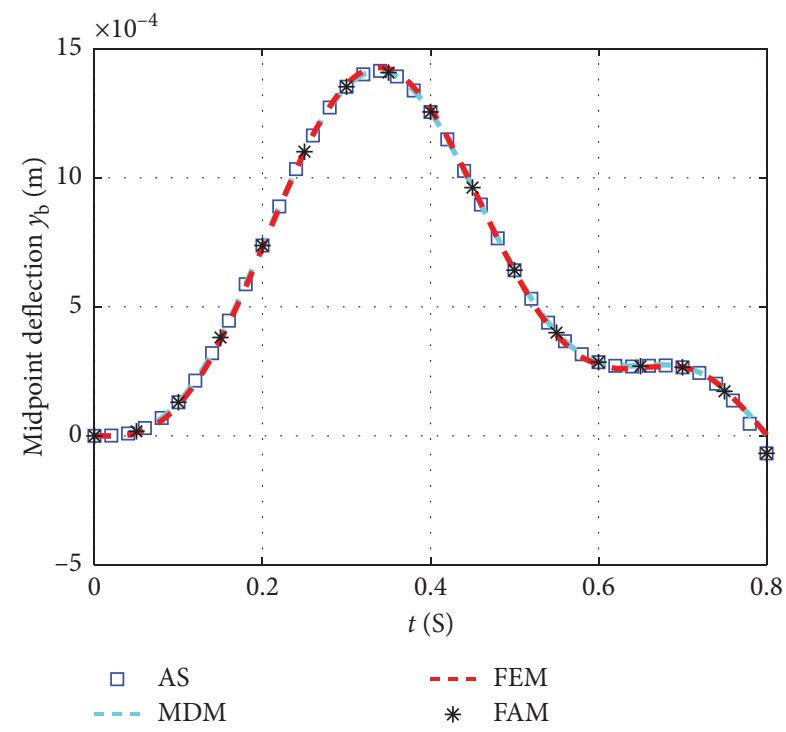

FIgURE 4: Midspan vertical displacement time history curve.

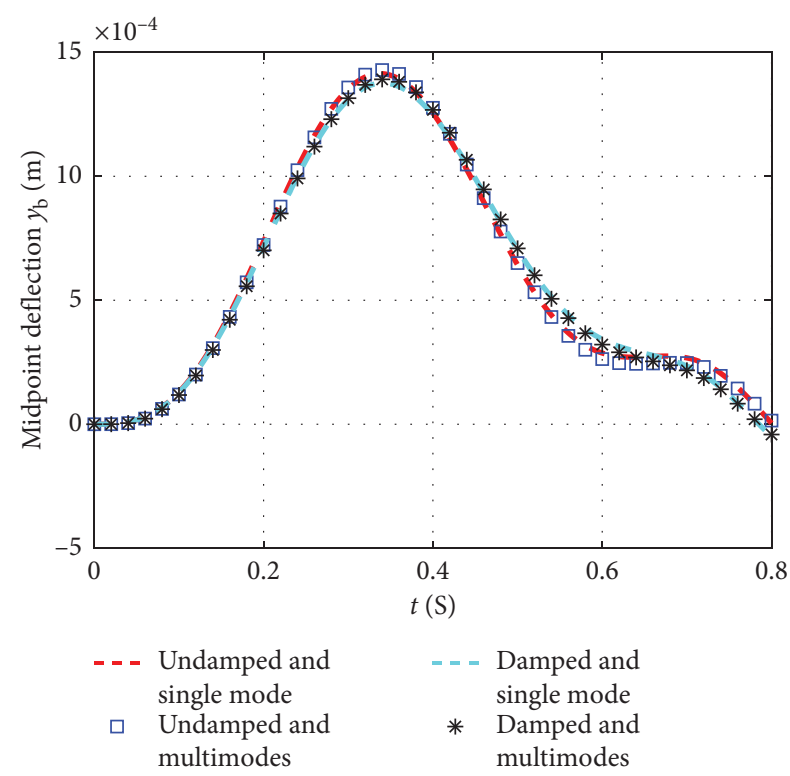

FIGURE 5: Effect of damping and modes on midspan vertical displacement.

bridge. This gives researchers the impression that utilizing only the first mode can yield generally good approximate solutions, especially when the midpoint deflection of the bridge is desired. Such an approximation neglecting damp and considering the first mode has been previously adopted by many researchers in their analytical studies.

The forced vibration of a bridge occurs only when the moving load acts on the bridge, and then, the free vibration of the bridge occurs and lasts for a period of time. For the two kinds of motions, the maximum values of the midpoint displacement response of the bridge under the moving load with different speeds are shown in Figure 6. For the same speed of the moving load, the displacement response maximums of the forced and free vibration are different obviously. For example, as can be seen from Figure 6, at the medium-speed stage (such as $40 \sim 90 \mathrm{~m} / \mathrm{s}$ ), the forced vibration maximums are not significantly different from those of free vibration response, while at the low-speed stage (such as $0 \sim 40 \mathrm{~m} / \mathrm{s}$ ), the maximums of the forced vibration response are much larger than those of the free vibration response. This is mainly due to the fact that at the low-speed stage, a moving load can act on the bridge for a long time, and the response of the forced vibration is composed of the steady-state reaction and the transient reaction, so the maximum values of the forced vibration response are much larger than the maximums from the free vibration response of the bridge. However, at the high-speed stage, a moving load may act on the bridge for a short period of time, so that the bridge does not react quickly and completely before the moving load leaves the bridge fast. Therefore, it can be found from Figure 6 that for the high-speed stage where the speeds are higher than $90 \mathrm{~m} / \mathrm{s}$, the maximum value of the free vibration response is gradually greater than that of the forced vibration response along with the speed increases.

Due to the fact that the time of free vibration is much longer than that of the corresponding forced vibration of a bridge under a moving load, it is significant to study the maximum amplitude of the free vibration for the railway bridge with a high-speed train. The proposed novel method based on the moving load spectrum in this paper can effectively analyze the speed of the moving load affecting the maximum amplitude of the bridge free vibration.

\subsection{A Single Moving Constant Force Exciting the Bridge Free Vibration}

4.1.1. Verification of Moving Load Spectrum. According to the bridge and load parameters in Table 2, the amplitude spectrums of moving constant force passing through the bridge at speeds of $50 \mathrm{~km} / \mathrm{h}, 100 \mathrm{~km} / \mathrm{h}, 200 \mathrm{~km} / \mathrm{h}$, and $326 \mathrm{~km} / \mathrm{h}$, namely, $\left|F_{\mathrm{b} 1}(\omega)\right|_{v=50 \mathrm{~km} / \mathrm{h}},\left|F_{\mathrm{b} 1}(\omega)\right|_{v=100 \mathrm{~km} / \mathrm{h}},\left|F_{\mathrm{b} 1}(\omega)\right|_{v=200 \mathrm{~km} / \mathrm{h}}$, and $\left|F_{\mathrm{b} 1}(\omega)\right|_{v=326 \mathrm{~km} / \mathrm{h}}$, are displayed in Figure 7. It shows that corresponding to the moving speed $50 \mathrm{~km} / \mathrm{h}$, the amplitude spectrum mainly distributes in the range of $0 \sim 7.62 \mathrm{rad} / \mathrm{s}$, while with the increase of moving speed, such as $200 \mathrm{~km} / \mathrm{h}$ and $326 \mathrm{~km} / \mathrm{h}$, the main distribution range enlarges, ranging from $0 \sim 26.16 \mathrm{rad} / \mathrm{s}$ to $0 \sim 42.73 \mathrm{rad} / \mathrm{s}$, respectively. Although the frequency range expands with the increase of moving load speed, the amplitude spectrum decreases in the lowfrequency part. It can be known from Figure 7 that at $\omega=\omega_{\mathrm{b} 1}=14.25 \mathrm{rad} / \mathrm{s}$, the amplitude spectrums corresponding to different velocities are $\left|F_{\mathrm{b} 1}(\omega)\right|_{v=50 \mathrm{~km} / \mathrm{h}}<$ $\left|F_{\mathrm{b} 1}(\omega)\right|_{v=100 \mathrm{~km} / \mathrm{h}}<\left|F_{\mathrm{b} 1}(\omega)\right|_{v=326 \mathrm{~km} / \mathrm{h}}<\left|F_{\mathrm{b} 1}(\omega)\right|_{v=200 \mathrm{~km} / \mathrm{h}}$. Apparently, according to equation (17), it can be known that the corresponding amplitude spectrums of the bridge vibration response are $\left|Y_{\mathrm{b}}\right|_{v=50 \mathrm{~km} / \mathrm{h}}<\left|Y_{\mathrm{b}}\right|_{v=100 \mathrm{~km} / \mathrm{h}}<$ $\left|Y_{\mathrm{b}}\right|_{v=326 \mathrm{~km}} / \mathrm{h}<\left|Y_{\mathrm{b}}\right|_{v=200 \mathrm{~km} / \mathrm{h}}$. It is noted that $\left|F_{\mathrm{b} 1}(\omega)\right|_{v=50 \mathrm{~km} / \mathrm{h}}$ 


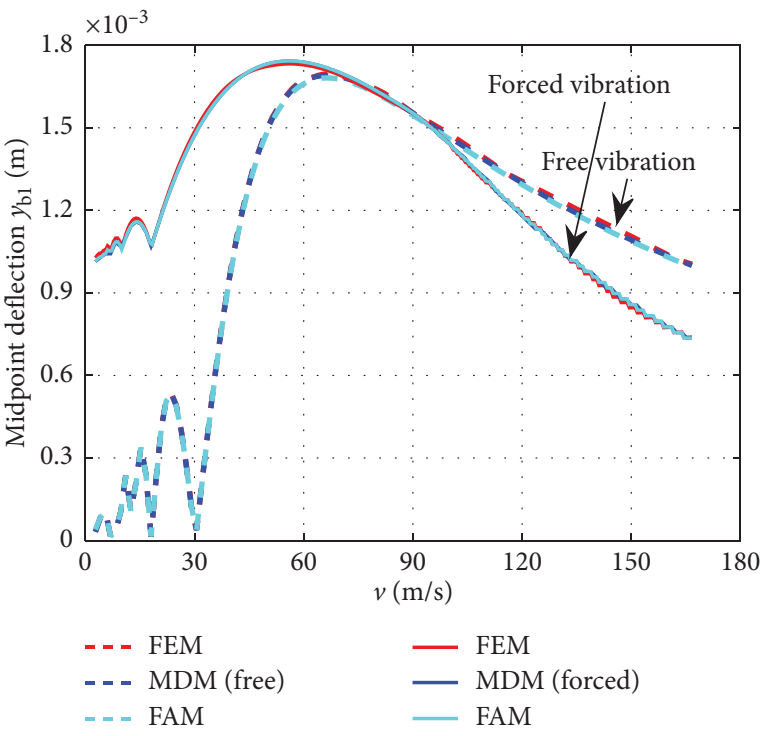

FIGURE 6: Maximums of the bridge vibration response versus different speeds.

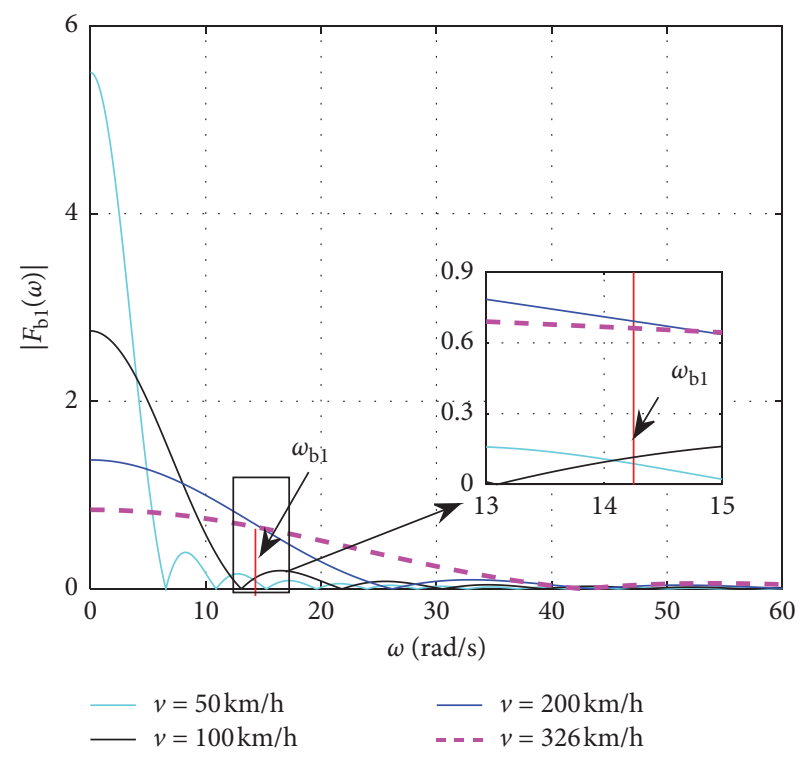

Figure 7: Amplitude spectrums of the moving constant loads.

and $\left|F_{\mathrm{b} 1}(\omega)\right|_{v=100 \mathrm{~km} / \mathrm{h}}$ are significantly smaller than $\left|F_{\mathrm{b} 1}(\omega)\right|_{v=326 \mathrm{~km} / \mathrm{h}}$ and $\left|F_{\mathrm{b} 1}(\omega)\right|_{v=200 \mathrm{~km} / \mathrm{h}}$, while $\left|F_{\mathrm{b} 1}(\omega)\right|_{v=326 \mathrm{~km} / \mathrm{h}}$ and $\left|F_{\mathrm{b} 1}(\omega)\right|_{v=50 \mathrm{~km} / \mathrm{h}}$ are less than $\left|F_{\mathrm{b} 1}(\omega)\right|_{v=200 \mathrm{~km} / \mathrm{h}}$ and $\left|F_{\mathrm{b} 1}(\omega)\right|_{v=100 \mathrm{~km} / \mathrm{h}}$, respectively, but the differences are not large.

In order to verify the correctness of the analysis based on the moving load spectrum in the frequency domain, the time history responses of the midpoint deflection (including free and forced vibrations) of the bridge under a moving constant force possessing the speeds such as $50 \mathrm{~km} / \mathrm{h}, 100 \mathrm{~km} / \mathrm{h}$, $200 \mathrm{~km} / \mathrm{h}$, and $326 \mathrm{~km} / \mathrm{h}$ are shown in Figure 8 . It can be observed that when the load moving speeds are $50 \mathrm{~km} / \mathrm{h}$ and $100 \mathrm{~km} / \mathrm{h}$, the amplitudes of the free vibration response of the bridge are significantly smaller than the amplitudes corresponding to the moving speeds $200 \mathrm{~km} / \mathrm{h}$ and $326 \mathrm{~km} / \mathrm{h}$.

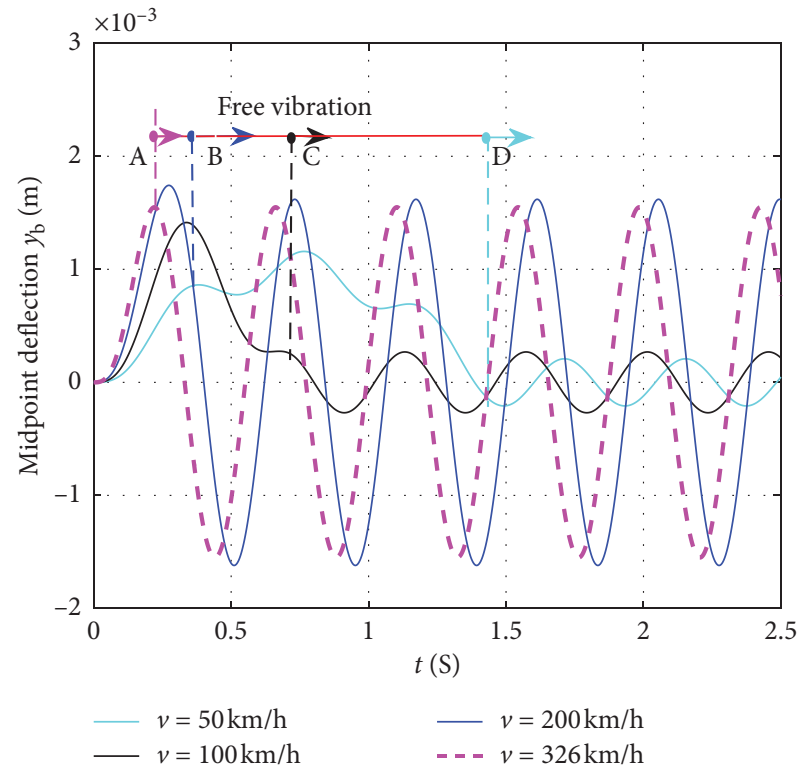

Figure 8: Vertical displacement of bridge span at different speeds.

Moreover, the bridge free vibration amplitudes for the load moving speeds $326 \mathrm{~km} / \mathrm{h}$ and $50 \mathrm{~km} / \mathrm{h}$ are slightly smaller than the amplitudes with regard to the load moving speeds $200 \mathrm{~km} / \mathrm{h}$ and $100 \mathrm{~km} / \mathrm{h}$, respectively. These results are completely consistent with those found based on the moving load spectrum as shown in Figure 7.

It is noted that the moving speed of $326 \mathrm{~km} / \mathrm{h}$ in the analysis is the resonant velocity $V_{\mathrm{res}}=\omega_{\mathrm{b} 1} L / \pi$. However, not only the amplitude of the free vibration is not the maximum, but also the amplitude of the forced vibration is not the maximum as shown in Figure 8. It verifies that the resonant speed of the moving load does not necessarily excite the bridge to produce the maximum response.

\subsubsection{Verification of the Moving Load Speed Corresponding to} the Maximum Free Vibration Response of a Bridge. It is an accepted idea that resonance is the maximum vibration response. However, for the vibration of a bridge under the moving load with resonant velocity, no resonance can occur since the force traverses the bridge for a finite time, that is, the maximum of the bridge response never occurs at the resonant velocity [30]. In this paper, a simple formula $V_{|Y| \max }=\omega_{\mathrm{b} 1} L / 4.34$ acquired through analyzing the maximum of $\left|F_{\mathrm{b} 1}\left(\omega_{\mathrm{b} 1}\right)\right|$ is proposed to calculate the moving load speed corresponding to the maximum free vibration response of a bridge. Besides, the other speeds corresponding to the extremism of the free vibration response can be obtained by the analysis on the extremism of $\left|F_{\mathrm{b} 1}\left(\omega_{\mathrm{b} 1}\right)\right|$ in the same way.

In order to verify the proposed speed formula and the other speeds corresponding to the extremism response, according to the bridge parameters in Table 2, the comparative analysis is made between the frequency domain and the time domain as shown in Figures 9 and 10, respectively. Figure 9 shows the amplitudes of a moving constant load at different speeds, while Figure 10 displays the displacement 


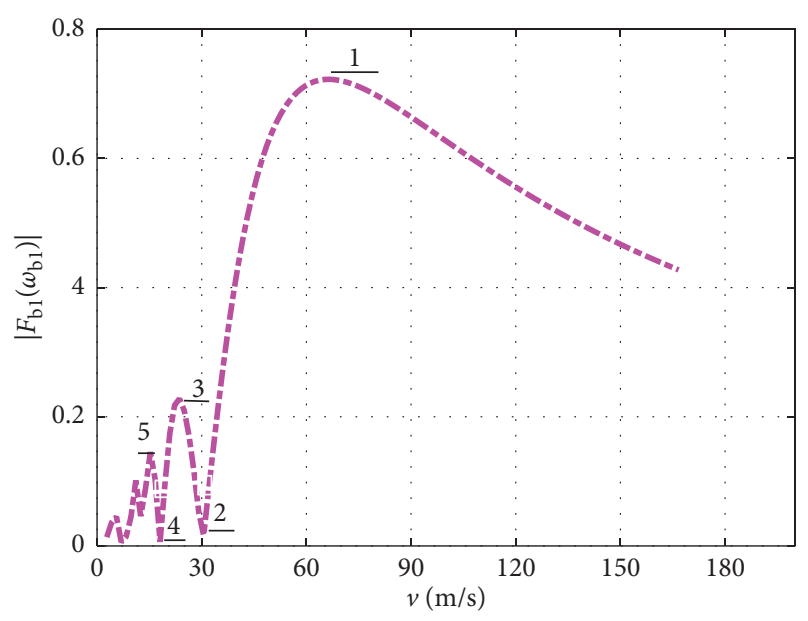

Figure 9: Amplitudes of moving constant load versus different speeds.

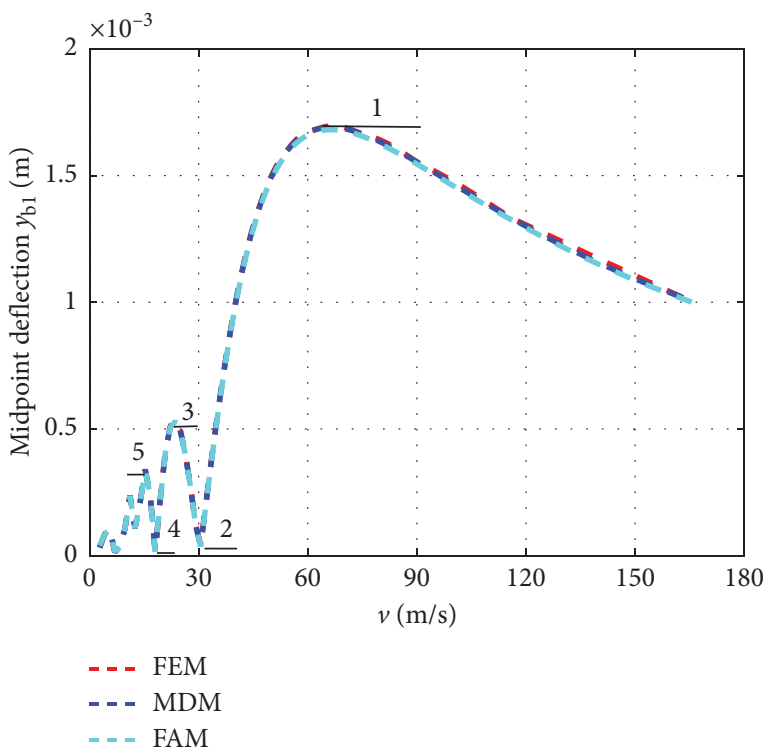

Figure 10: Amplitudes of the bridge free vibration response versus different speeds.

amplitudes of the bridge free vibration response solved in the time domain by MDM, FEM, and FAM concerning the different speeds of the moving load. By comparing Figures 9 and 10 , it can be found that the moving load speed corresponding to the maximum amplitude of the moving load is identical to that corresponding to the maximum amplitude of the free vibration displacement response. Obviously, this speed coincides with $65.65 \mathrm{~m} / \mathrm{s}$ calculated by the proposed formula (22). It should be pointed out that such a critical speed is rarely noticed since it is different from the resonant velocity $V_{\text {res }}=\omega_{\mathrm{b} 1} L / \pi=90.7 \mathrm{~m} / \mathrm{s}$, or $326 \mathrm{~km} / \mathrm{h}$, which in fact never induces the maximum of the bridge response. Besides, the load moving speeds corresponding to other extreme points of the free vibration displacement response in Figure 10 have a good agreement with the speeds corresponding to other extreme points of the moving load amplitudes in
TABLE 3: Speeds corresponding to the extreme points of $\left|F_{\mathrm{b} 1}(\kappa)\right|$.

\begin{tabular}{lcc}
\hline Local maximum point & $\kappa$ & $\mathrm{V}(\mathrm{m} / \mathrm{s})$ \\
\hline 1 & 4.34 & 65.65 \\
2 & 9.42 & 30.25 \\
3 & 12.15 & 23.44 \\
4 & 15.70 & 18.15 \\
5 & 18.66 & 15.27 \\
\hline
\end{tabular}

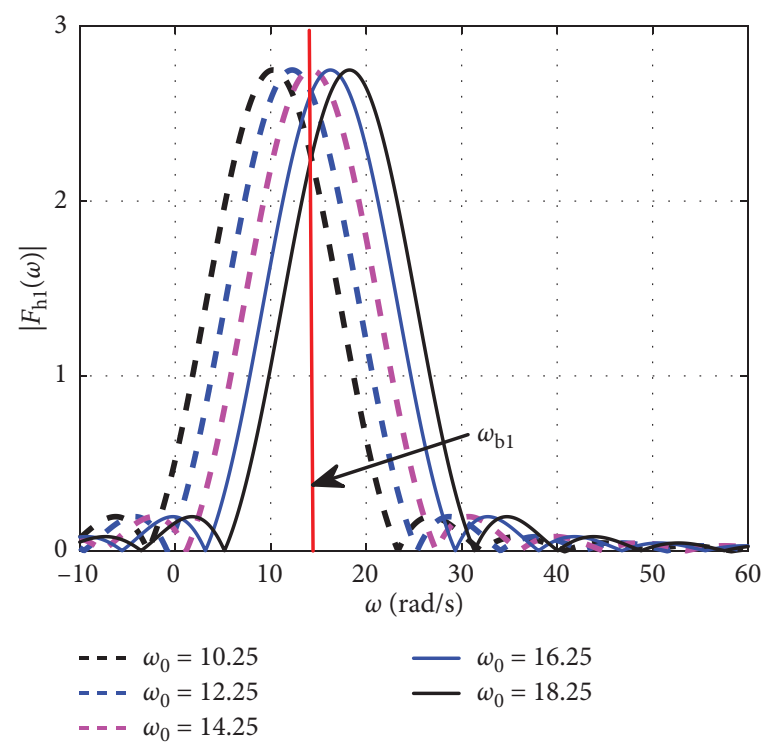

FIGURE 11: Amplitude spectrum of a moving harmonic load with different frequencies $\omega_{0}$.

Figure 9, and these speeds listed in Table 3 are related to the fundamental frequency and span of the bridge.

\subsection{A Single Moving Harmonic Force Exciting the Bridge Free Vibration}

4.2.1. Verification of Moving Load Spectrum. By comparing equations (18) and (23), it can be found that equation (23) is the same as equation (18) when the harmonic frequency $\omega_{0}=0$. That is, the amplitude spectrum of the moving harmonic load can be obtained by shifting a harmonic frequency $\omega_{0}$ to the right in the horizontal coordinate as shown in Figure 11. Furthermore, as can be seen from Figure 11, the harmonic frequency $\omega_{0}$ is closer to the bridge fundamental frequency $\omega_{\mathrm{b} 1}$, the corresponding amplitude spectrum of the moving harmonic load is larger, for example, $\quad\left|F_{\mathrm{h} 1} \quad\left(\omega_{\mathrm{b} 1}\right)\right|_{\omega 0=10.25 \mathrm{rad} / \mathrm{s}}<\left|F_{\mathrm{h} 1} \quad\left(\omega_{\mathrm{b} 1}\right)\right|_{\omega 0=12.25 \mathrm{rad} / \mathrm{s}}<$ $\left|F_{\mathrm{h} 1}\left(\omega_{\mathrm{b} 1}\right)\right|_{\omega 0=14.25 \mathrm{rad} / \mathrm{s}}$. Moreover, it can also be seen that the amplitudes $\left|F_{\mathrm{h} 1}\left(\omega_{\mathrm{b} 1}\right)\right|$ corresponding to the symmetrical harmonic frequencies about the bridge fundamental frequency are the same, such as $\left|F_{\mathrm{h} 1}\left(\omega_{\mathrm{b} 1}\right)\right|_{\omega 0=10.25 \mathrm{rad} / \mathrm{s}}=$ $\left|F_{\mathrm{h} 1} \quad\left(\omega_{\mathrm{b} 1}\right)\right|_{\omega 0=18.25 \mathrm{rad} / \mathrm{s}}$ and $\mid F_{\mathrm{h} 1} \quad\left(\omega_{\mathrm{b} 1}\right)$ $\left.\right|_{\omega 0=12.25 \mathrm{rad} / \mathrm{s}}=\left|F_{\mathrm{h} 1}\left(\omega_{\mathrm{b} 1}\right)\right|_{\omega 0=16.25 \mathrm{rad} / \mathrm{s}}$.

In order to confirm the validity of the analysis based on the moving harmonic load spectrum in the frequency domain, the displacement vibration responses of the bridge at the speed 
TABLE 4: Selected five frequencies $\omega_{0}$ of the moving harmonic load.

\begin{tabular}{lccccc}
\hline Number & 1 & 2 & 3 & 4 & 5 \\
\hline$\omega_{0}(\mathrm{rad} / \mathrm{s})$ & 10.25 & 12.25 & 14.25 & 16.25 & 18.25 \\
\hline
\end{tabular}

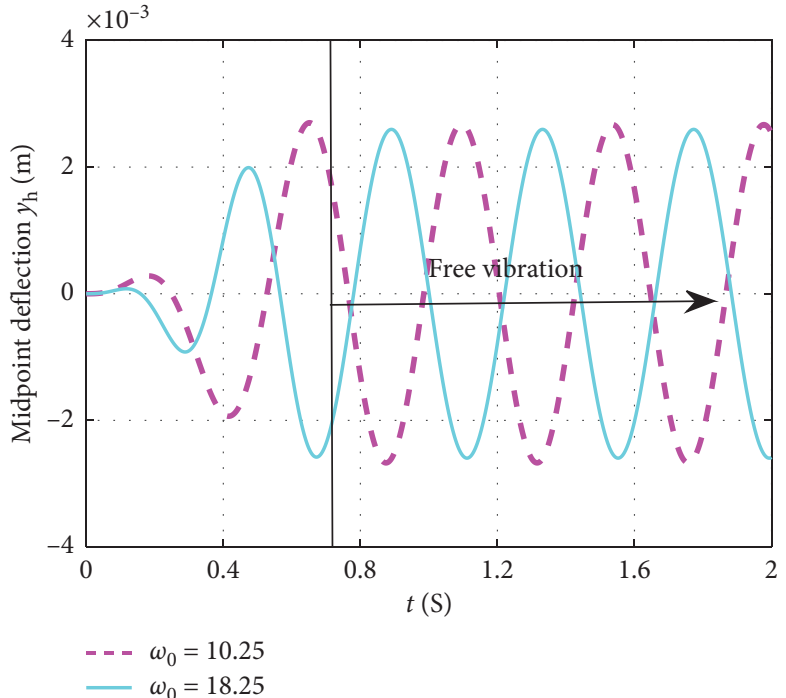

(a)

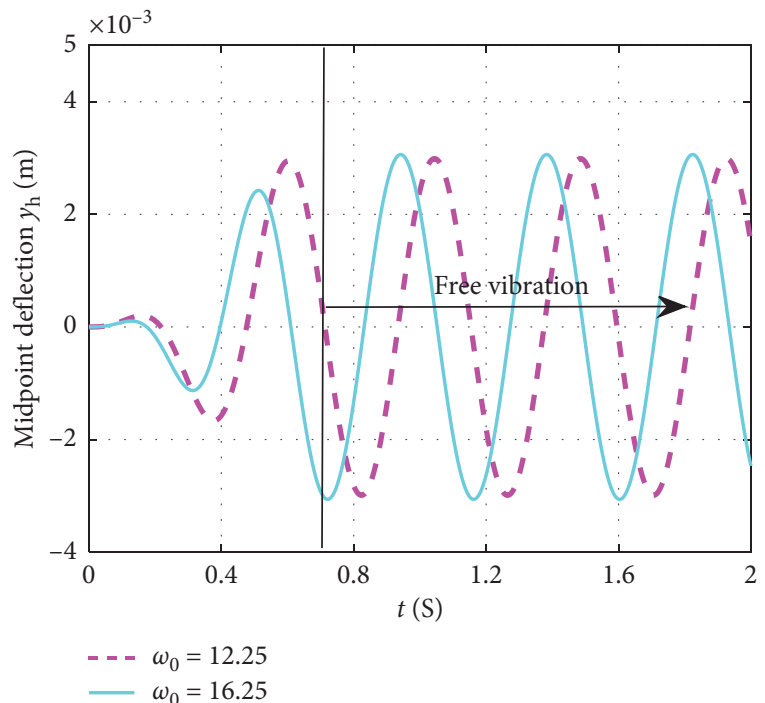

(b)

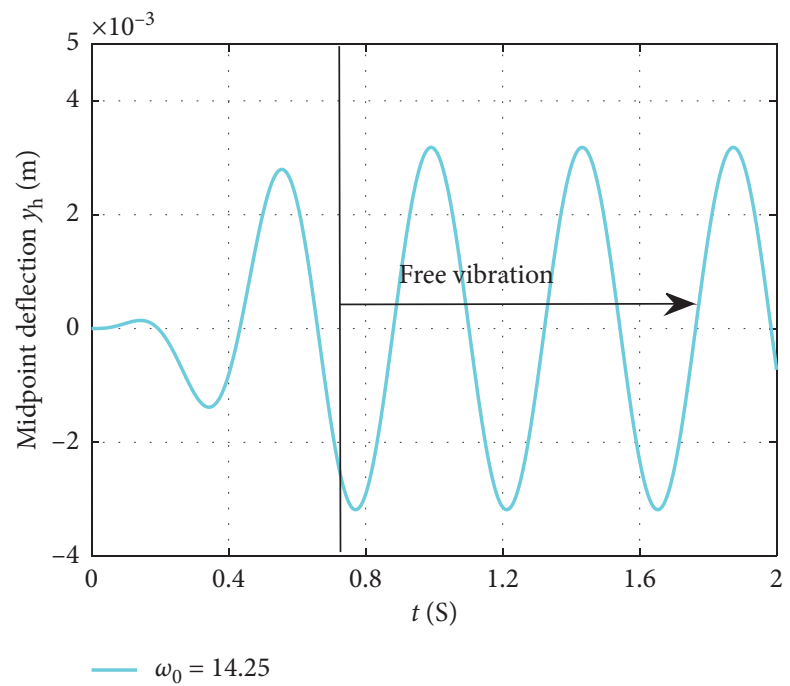

(c)

FIgURE 12: Time history curve of vertical displacement at bridge midspan.

$100 \mathrm{~km} / \mathrm{h}$ of a simple harmonic force possessing different frequencies listed in Table 4 are shown in Figure 12. It can be observed from the figure that the closer the harmonic frequency $\omega_{0}$ is to $\omega_{\mathrm{b} 1}$, the larger the amplitude of the free vibration response of the bridge midspan, such as, $\max \left\{y_{\mathrm{h}}(L /\right.$ $\left.2, t)_{\omega 0=10.25 \mathrm{rad} / \mathrm{s}}\right\}<\max \left\{y_{\mathrm{h}}(L / 2, t)_{\omega 0=12.25 \mathrm{rad} / \mathrm{s}}\right\}<\max \left\{y_{\mathrm{h}}(L /\right.$ $2, t)_{\omega 0=14.25 \mathrm{rad} / \mathrm{s}}$, which is corresponding to $\mid F_{\mathrm{h} 1}$ $\left.\left(\omega_{\mathrm{b} 1}\right)\right|_{\omega 0=10.25 \mathrm{rad} / \mathrm{s}}<\left|F_{\mathrm{h} 1} \quad\left(\omega_{\mathrm{b} 1}\right)\right|_{\omega 0=12.25 \mathrm{rad} / \mathrm{s}}<\mid F_{\mathrm{h} 1} \quad\left(\omega_{\mathrm{b} 1}\right)$ $\left.\right|_{\omega 0=14.25 \mathrm{rad} / \mathrm{s}}$ in Figure 11. And when the harmonic frequency of a moving harmonic load is symmetric about the bridge fundamental frequency, the amplitudes of the bridge free vibration at the midspan are equal, for example, $\max \left\{y_{\mathrm{h}}\right.$
$\left.(L / 2, t)_{\omega 0=10.25 \mathrm{rad} / \mathrm{s}}\right\}=\max \left\{y_{\mathrm{h}}(L / 2, t)_{\omega 0=18.25 \mathrm{rad} / \mathrm{s}}\right\}$ and $\max$ $\left\{y_{\mathrm{h}}(L / 2, t)_{\omega 0=12.25 \mathrm{rad} / \mathrm{s}}\right\}=\max \left\{y_{\mathrm{h}}(L / 2, t)_{\omega 0=16.25 \mathrm{rad} / \mathrm{s}}\right\}$. These above results displayed in Figure 12 are completely consistent with those found based on the moving harmonic load spectrum in Figure 11. Therefore, it confirms the validity of the analysis based on the moving harmonic load spectrum in the frequency domain.

4.2.2. Verification of the Moving Load Speed Corresponding to the Maximum Free Vibration Response of a Bridge. All the harmonic frequencies in Table 4 are selected for verification as shown in Figures 13 and 14. Comparing 


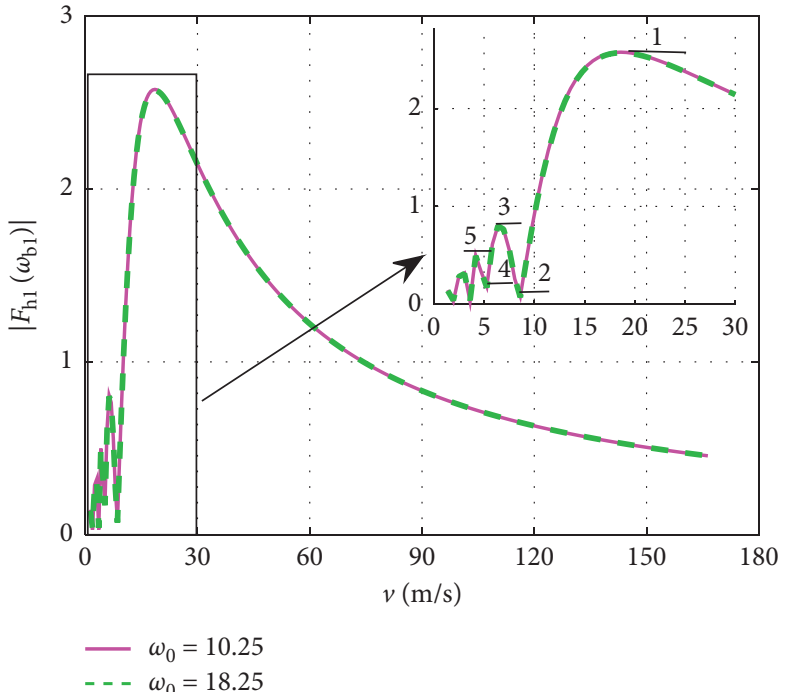

(a)

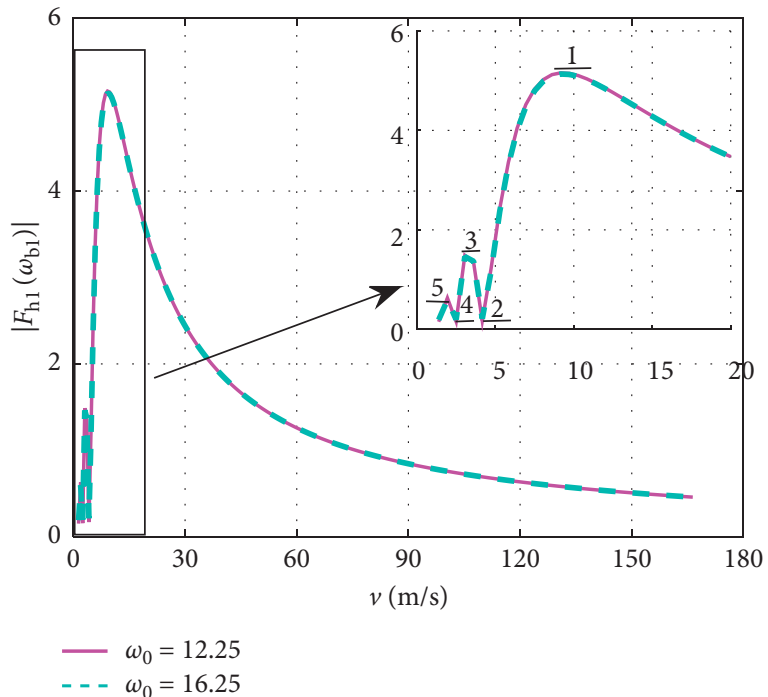

(b)

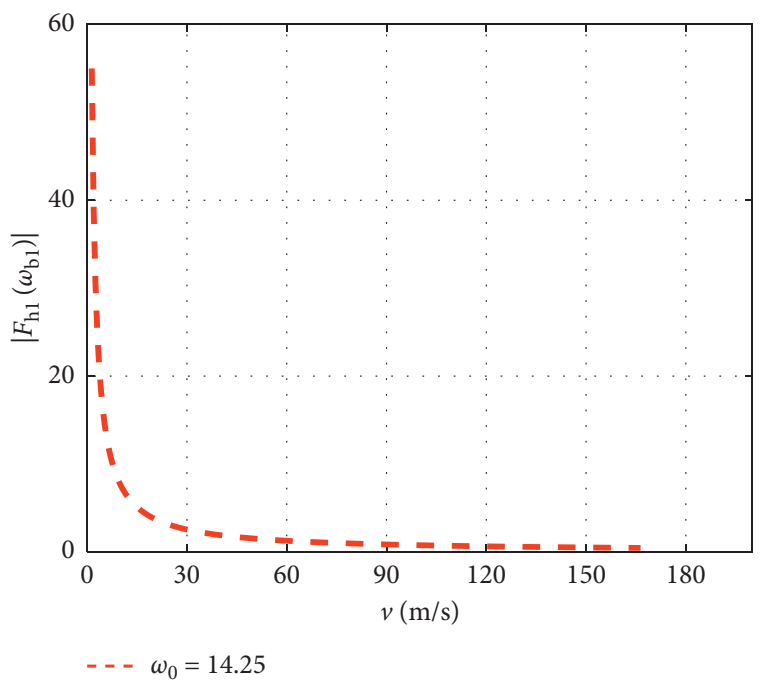

(c)

Figure 13: Amplitudes of the moving harmonic loads with different frequencies versus different speeds.

Figures 13 and 14, it can also be seen that for the different harmonic frequencies, the speeds at the extreme points of the moving harmonic load amplitudes are in one-to-one correspondence with those at the extreme values of the bridge free vibration amplitudes. So, the speeds corresponding to the maximum displacements of the bridge free vibration can be obtained by using equation (25), and they are listed in Table 5.

As shown in Figures 13(a) and 13(b) and Figures 14(a) and 14(b), the closer the harmonic frequency is to the bridge fundamental frequency, the larger the maximum amplitudes of both the moving harmonic load and the displacement response of the bridge free vibration are, such as $\max \left\{\mid F_{\mathrm{h} 1}\left(\omega_{\mathrm{b} 1}\right)\right.$ $\left.\left.\right|_{\omega 0=10.25 \mathrm{rad} / \mathrm{s}}\right\}<\max \left\{\left|F_{\mathrm{h} 1}\left(\omega_{\mathrm{b} 1}\right)\right|_{\omega 0=12.25 \mathrm{rad} / \mathrm{s}}\right\}$ and $\max \left\{y_{\mathrm{h}} \quad(L /\right.$ $\left.2, t)_{\omega 0=10.25 \mathrm{rad} / \mathrm{s}}\right\}<\max \left\{y_{\mathrm{h}} \quad(L / 2, t)_{\omega 0=12.25 \mathrm{rad} / \mathrm{s}}\right\}$; however, the smaller the corresponding moving load speed is. Also, for the symmetrical harmonic frequencies concerning the bridge fundamental frequency, the corresponding displacement amplitudes of the bridge free vibration are consistent with each other, and the corresponding amplitudes of the moving harmonic load also agree with each other.

Besides, in Figures 13(c) and 14(c), for the harmonic frequency $\omega=\omega_{\mathrm{b} 1}=14.25 \mathrm{rad} / \mathrm{s}$, bridge resonance response occurs when the moving harmonic load is static and acts on the bridge. However, the resonance disappears due to the influence of the speed of the moving harmonic load. Also, the amplitude response decreases with the increase of the moving load speed as shown in Figure 14(c). Similarly, the amplitude of the moving harmonic load in Figure 13(c) also decreases with the increase of the speed of the moving load. These results are reflected in the proposed speed formula (25) corresponding to the maximum response of bridge free vibration. 

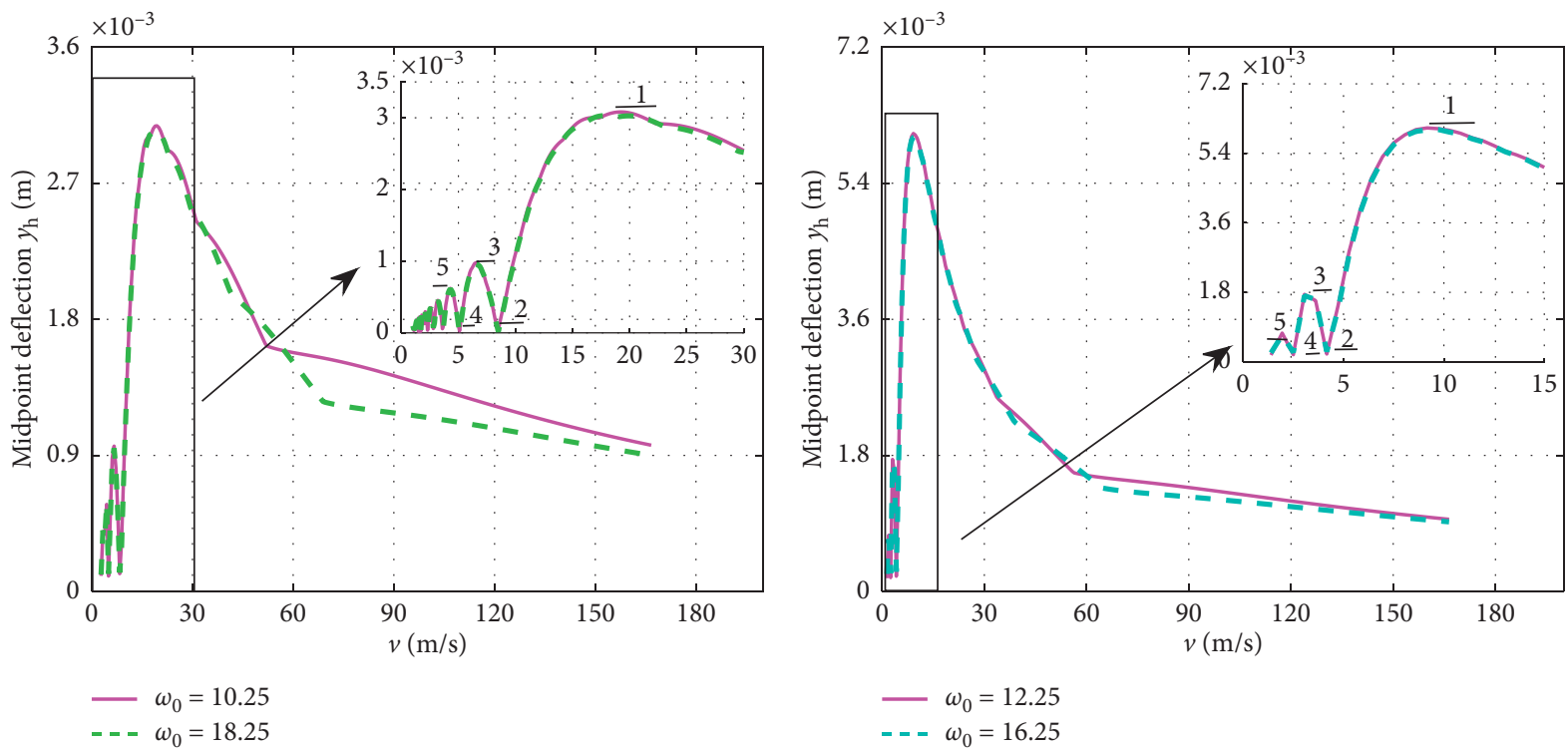

(a)

(b)

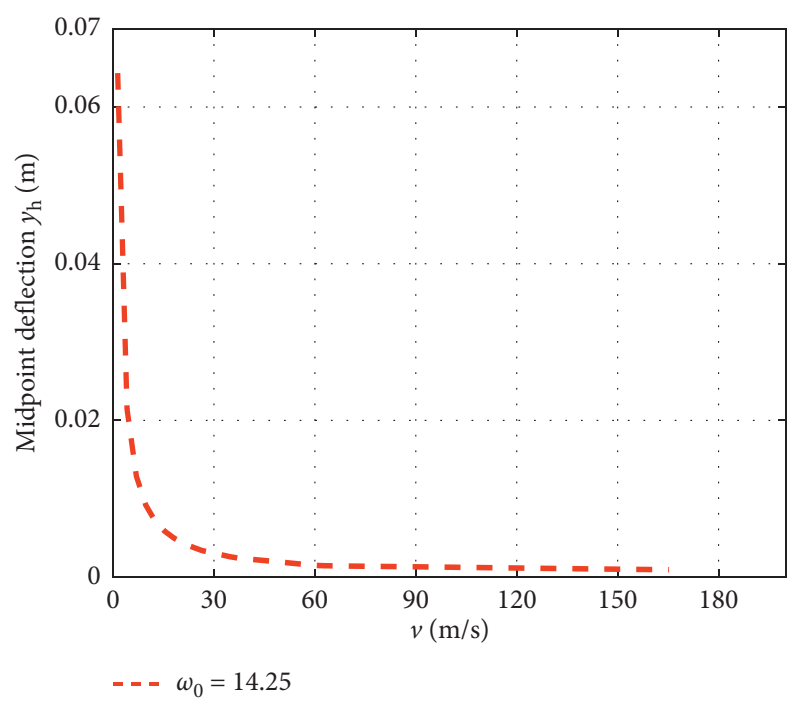

(c)

Figure 14: Displacement amplitudes of the bridge free vibration response versus different speeds of the moving load with different frequencies.

TABLE 5: Speeds of the moving harmonic load with $\omega_{0}$ corresponding to the bridge maximum response.

\begin{tabular}{lccccc}
\hline$\omega_{0}(\mathrm{rad} / \mathrm{s})$ & 10.25 & 12.25 & 14.25 & 16.25 & 18.25 \\
\hline Speeds in Figure 13 (m/s) & 18.43 & 9.21 & 0 & 9.21 & 18.43 \\
Speeds in Figure 14 (m/s) & 19.23 & 9.35 & 0 & 9.57 & 17.80 \\
\hline
\end{tabular}

\section{Conclusions}

Based on the moving load spectrum deduced from Fourier transform in this paper, a novel method is proposed to analyze the extreme response of bridge free vibration under a traveling load such as single moving constant force and harmonic force. By analyzing the moving load spectrum in detail, it has been shown that there exists a unique expression describing the dependence of the free vibration maximum response of a simply supported bridge on the speed of the moving load in this paper. This expression can be quite useful for design engineers and researchers without intensive computations to conveniently and quickly assess the speed of a moving load corresponding to the maximum response of the free vibration. In the fourth section of this paper, the moving load spectrum deduced for the first time and the presented formulas are validated by a large number of calculation results in the time domain, and the following conclusions are drawn:

The moving load spectrum deduced through the Fourier transform in the frequency domain affects directly the magnitude of bridge free vibration response. 
The speeds corresponding to the extreme points in the moving load spectrum are consistent with those corresponding to the extreme points of the bridge vibration response obtained in the time domain. For a traveling constant force, the moving speed expressed by the presented formula (23) in the paper can cause the maximum response of the bridge free vibration, and it is related not only to the fundamental frequency of the bridge but also to the span.

Further considering the effect of the natural frequency of the moving load, for a moving harmonic force, the corresponding load speed formulated as equation (25) in this paper can excite the maximum response of the bridge free vibration, and it is related not only to the fundamental frequency and span of bridge but also to the harmonic frequency of the moving harmonic load. Moreover, the closer the harmonic frequency is to the natural frequency of the bridge, the greater the free vibration response of the bridge is, while the corresponding moving speed of the harmonic load decreases relatively.

However, these above speeds resulting in the maximum response of the bridge free vibration are different from the resonant velocity $V_{\text {res }}=\omega_{\mathrm{b} 1} L / \pi$. In fact, after a moving load passes through a bridge at the resonant speed, the forced and free vibration responses of the bridge are not the largest.

For the moving load with the natural frequency, the bridge resonance response may not be excited when the harmonic frequency of the moving is equal to the fundamental frequency of the bridge. It happens only when the moving load possessing bridge frequency is static and always acts on the bridge.

\section{Data Availability}

All data generated or analyzed during this study are included in this article. And all data included in this study are available upon request by contact with the corresponding author.

\section{Conflicts of Interest}

The authors declare that they have no conflicts of interest.

\section{Acknowledgments}

The authors acknowledge the financial contributions received from the National Natural Science Foundation of China (no. 11962006) and the Natural Science Foundation of Jiangxi Province (no. 2017BAB206051).

\section{References}

[1] L. Jiang, Y. Feng, W. Zhou, and B. He, "Vibration characteristic analysis of high-speed railway simply supported beam bridge-track structure system," Steel and Composite Structures, vol. 31, no. 6, pp. 591-600, 2019.
[2] L. Frýba, "A rough assessment of railway bridges for high speed trains," Engineering Structures, vol. 23, no. 5, pp. 548556, 2001.

[3] C. C. Lin, J. F. Wang, and B. L. Chen, "Train-induced vibration control of high-speed railway bridges equipped with multiple tuned mass dampers," Journal of Bridge Engineering, vol. 10, no. 4, pp. 398-414, 2005.

[4] Y. Feng, L. Jiang, W. Zhou, Z. Lai, and X. Chai, "An analytical solution to the mapping relationship between bridge structures vertical deformation and rail deformation of high-speed railway," Steel and Composite Structures, vol. 33, no. 2, pp. 209-224, 2019.

[5] L. F. F. Miguel, R. H. Lopez, and A. J. Torii, "Robust design optimization of TMDs in vehicle-bridge coupled vibration problems," Engineering Structures, vol. 126, pp. 703-711, 2016.

[6] A. Y. Pisal and R. S. Jangid, "Vibration control of bridge subjected to multi-axle vehicle using multiple tuned mass friction dampers," International Journal of Advanced Structural Engineering, vol. 8, no. 2, pp. 213-227, 2016.

[7] R. Willis, Report of the Commissioners Appointed to Inquire into the Application of Iron to Railway Structures, William Clowes and Sons, London, UK, 1849.

[8] L. Maunder, "On the work of a force crossing a beam," Quarterly of Applied Mathematics, vol. 17, no. 4, pp. 437-439, 1960 .

[9] W. Weaver, S. P. Timoshenko, and D. H. Young, Vibration Problems in Engineering, Wiley, Hoboken, NJ, USA, 5th edition, 1990.

[10] J. A. Gbadeyan and S. T. Oni, "Dynamic behaviour of beams and rectangular plates under moving loads," Journal of Sound and Vibration, vol. 182, no. 5, pp. 677-695, 1995.

[11] L. Frýba, Dynamics of Railway Bridges, Thomas Telford, London, UK, 1996.

[12] G. T. Michaltsos, "The influence of centripetal and Coriolis forces on the dynamic response of light bridges under moving vehicles," Journal of Sound and Vibration, vol. 247, no. 2, pp. 261-277, 2001.

[13] E. Savin, "Dynamic amplification factor and response spectrum for the evaluation of vibrations of beams under successive moving loads," Journal of Sound and Vibration, vol. 248, no. 2, pp. 267-288, 2001.

[14] J. Li and M. Su, "The resonant vibration for a simply supported girder bridge under high-speed trains," Journal of Sound and Vibration, vol. 224, no. 5, pp. 897-915, 1999.

[15] X. Z. Li and S. Z. Qiang, "Dynamic Response of long span cable-stayed bridge subjected to moving high-speed train," IABSE Symposium Report, vol. 87, no. 10, pp. 59-65, 2003.

[16] N. Zhang, H. Xia, and W. Guo, "Vehicle-bridge interaction analysis under high-speed trains," Journal of Sound and Vibration, vol. 309, no. 3-5, pp. 407-425, 2008.

[17] H. Xia, J. Chen, P. Wei, C. Xia, G. De Roeck, and G. Degrande, "Experimental investigation of railway train-induced vibrations of surrounding ground and a nearby multi-story building," Earthquake Engineering and Engineering Vibration, vol. 8, no. 1, pp. 137-148, 2009.

[18] H. Li, H. Xia, M. Soliman, and D. M. Frangopol, "Bridge stress calculation based on the dynamic response of coupled trainbridge system," Engineering Structures, vol. 99, pp. 334-345, 2015.

[19] S. H. Ju and H. T. Lin, "Resonance characteristics of highspeed trains passing simply supported bridges," Journal of Sound and Vibration, vol. 267, no. 5, pp. 1127-1141, 2003.

[20] Y. B. Yang, C. L. Lin, J. D. Yau, and D. W. Chang, "Mechanism of resonance and cancellation for train-induced vibrations on 
bridges with elastic bearings," Journal of Sound and Vibration, vol. 269, no. 1-2, pp. 345-360, 2004.

[21] J. D. Yau and Y. B. Yang, "Vertical accelerations of simple beams due to successive loads traveling at resonant speeds," Journal of Sound and Vibration, vol. 289, no. 1-2, pp. 210-228, 2006.

[22] L. Mao and Y. Lu, "Critical speed and resonance criteria of railway bridge response to moving trains," Journal of Bridge Engineering, vol. 18, no. 2, pp. 131-141, 2011.

[23] M. Luu, V. Zabel, and C. Könke, "An optimization method of multi-resonant response of high-speed train bridges using TMDs," Finite Elements in Analysis and Design, vol. 53, pp. 13-23, 2012.

[24] J.-F. Lu, X. Sha, and J.-B. Wu, "Resonance and cancellation phenomena caused by equidistant moving loadings in a periodic structure - a pile-supported periodic viaduct," European Journal of Mechanics, vol. 59, pp. 114-123, 2016.

[25] Y. B. Yang and J. D. Yau, "Resonance of high-speed trains moving over a series of simple or continuous beams with nonballasted tracks," Engineering Structures, vol. 143, pp. 295305, 2017.

[26] Y. J. Wang, Q. C. Wei, and J. D. Yau, "Interaction response of train loads moving over a two-span continuous beam," International Journal of Structural Stability and Dynamics, vol. 13, no. 01, p. 1350002, 2013.

[27] W. He, "Vertical dynamics of a single-span beam subjected to moving mass-suspended payload system with variable speeds," Journal of Sound and Vibration, vol. 418, pp. 36-54, 2018.

[28] H. Xia, N. Zhang, and W. W. Guo, "Analysis of resonance mechanism and conditions of train-bridge system," Journal of Sound and Vibration, vol. 297, no. 3-5, pp. 810-822, 2006.

[29] H. Xia, N. Zhang, and W. W. Guo, Dynamic Interaction of Train-Bridge Systems in High-Speed Railways, Beijing Jiaotong University Press and Springer-Verlag GmbH Germany, Beijing, China, 2018.

[30] A. V. Pesterev, B. Yang, L. A. Bergman, and C. A. Tan, "Revisiting the moving force problem," Journal of Sound and Vibration, vol. 261, no. 1, pp. 75-91, 2003.

[31] P. Museros, E. Moliner, and M. D. Martínez-Rodrigo, "Free vibrations of simply-supported beam bridges under moving loads: maximum resonance, cancellation and resonant vertical acceleration," Journal of Sound and Vibration, vol. 332, no. 2, pp. 326-345, 2013.

[32] C. P. S. Kumar, C. Sujatha, and K. Shankar, "Vibration of simply supported beams under a single moving load: a detailed study of cancellation phenomenon," International Journal of Mechanical Sciences, vol. 99, pp. 40-47, 2015.

[33] Y. B. Yang, Vehicle-bridge Interaction Dynamics: With Applications to High-Speed Railways, World Scientific, Singapore, 2004. 


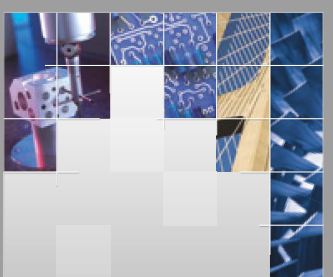

\section{Enfincering}
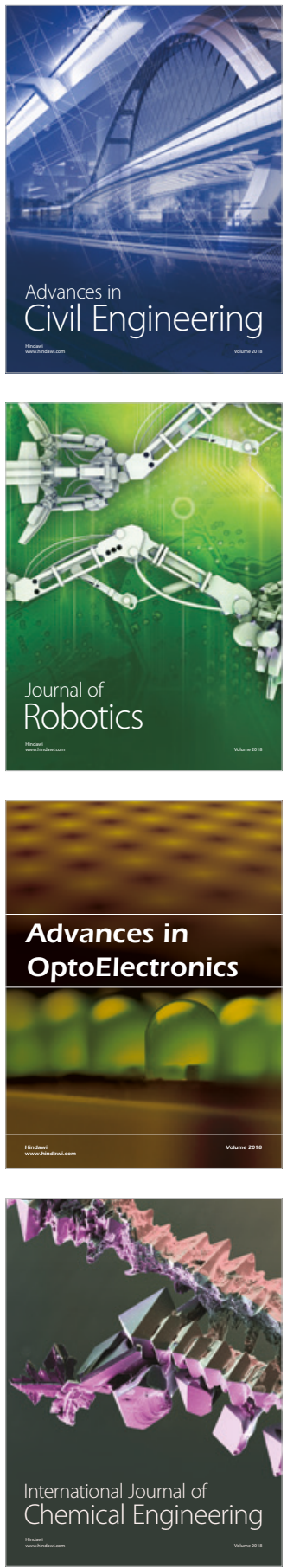

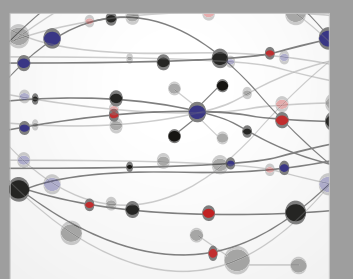

\section{Rotating \\ Machinery}

The Scientific World Journal

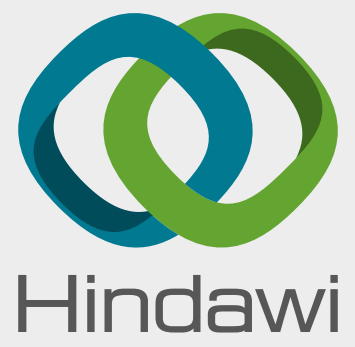

Submit your manuscripts at

www.hindawi.com
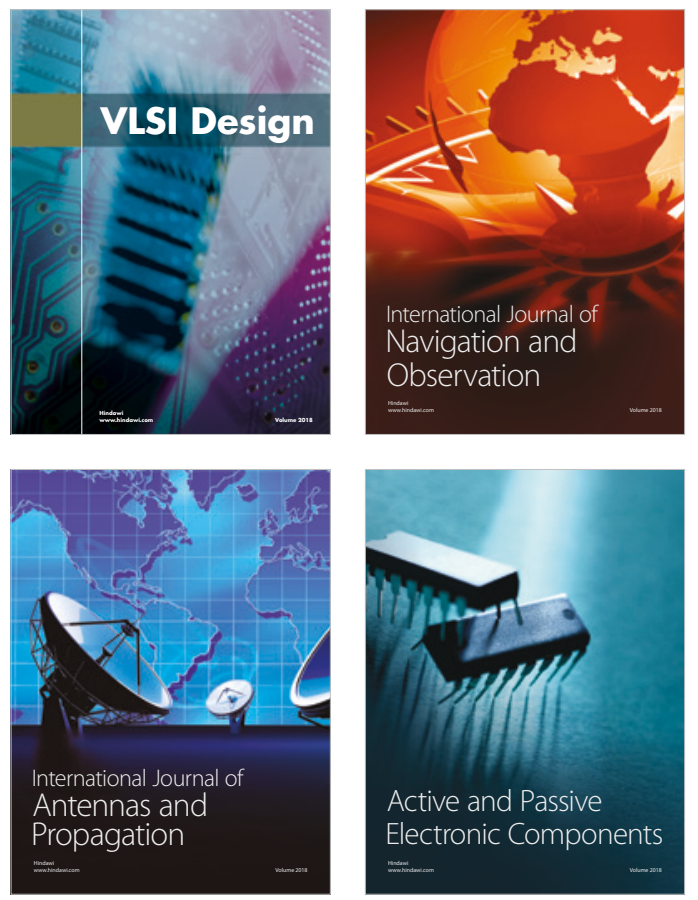
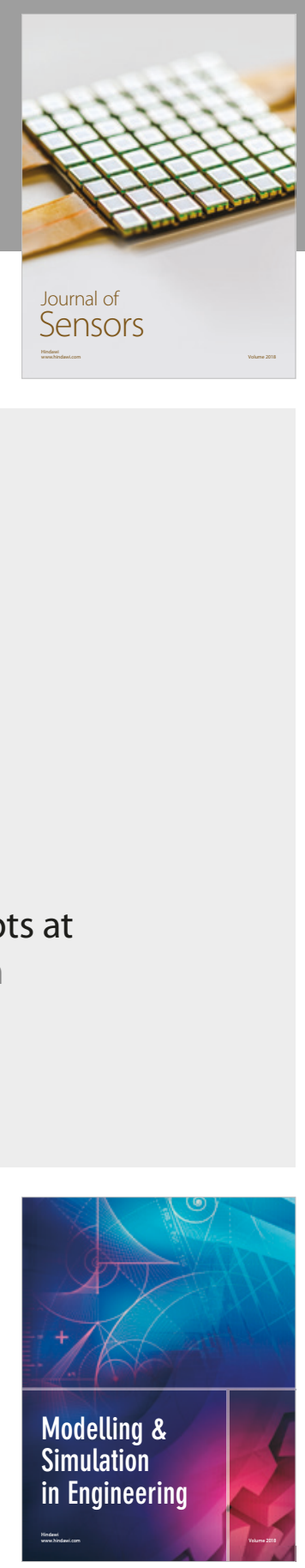

\section{Advances \\ Multimedia}
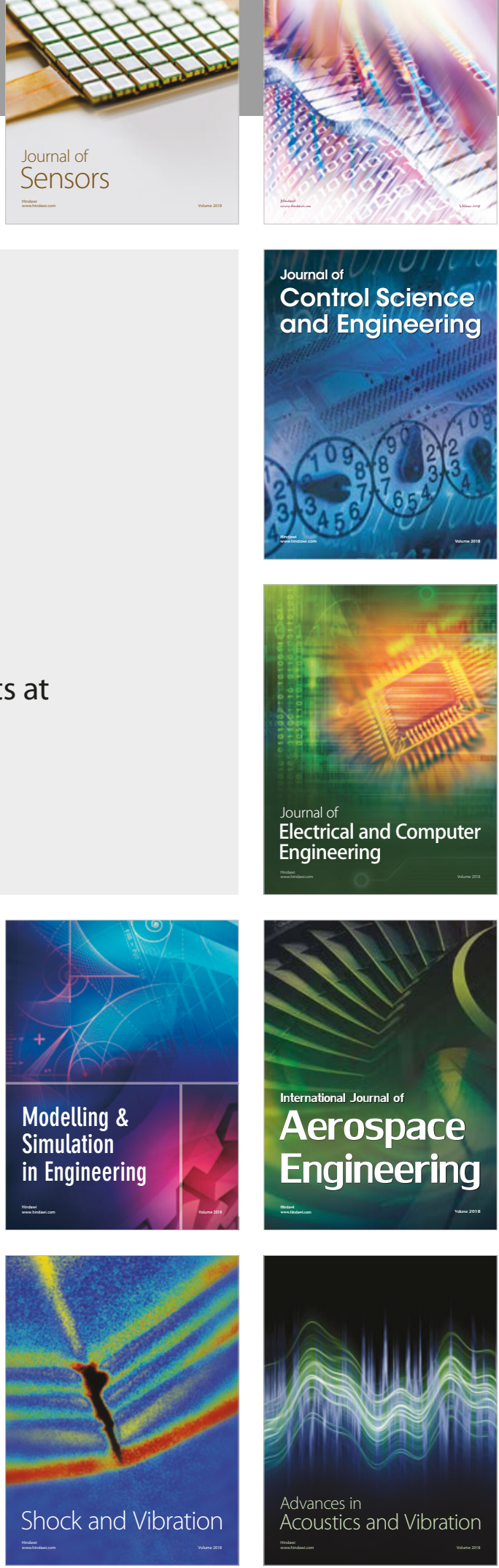